\title{
MATERIAL ANALYSIS OF OUTER DOOR HANDLES OF THE HISTORICAL CAR TATRA 87
}

\author{
${ }^{1}$ Lukáš KUDRNA, ${ }^{2}$ Petra VÁŇOVÁ, ${ }^{3}$ Jitka MALCHARCZIKOVÁ, ${ }^{4}$ Tomáš KUBÍN \\ ${ }^{1}$ VSB - Technical University of Ostrava, Department of Production Machines and Design, Ostrava, \\ Czech Republic, EU, lukas.kudrna@vsb.cz \\ ${ }^{2}$ VSB - Technical University of Ostrava, Department of Material Engineering, Ostrava, Czech Republic, EU, \\ petra.vanova@vsb.cz \\ ${ }^{3}$ VSB - Technical University of Ostrava, Department of Material Engineering, Ostrava, Czech Republic, EU, \\ jitka.malcharczikova@vsb.cz \\ ${ }^{4}$ VSB - Technical University of Ostrava, Department of Production Machines and Design, Ostrava, \\ Czech Republic, EU, tomas.kubin@vsb.cz
}

https://doi.org/10.37904/metal.2020.3503

\begin{abstract}
This article is about the chemical composition and microstructure of the outer door handles of the TATRA 87. The TATRA 87 was produced between 1937 and 1950. It was a timeless car with an aerodynamic selfsupporting body and an eight-cylinder engine mounted at the rear. The material analysis was carried out on four pieces of historical outer door handles of different ages and conditions. These were door handle lent by the ECORRA s. r. o. company. The chemical composition of all four door handles was detected with an X-ray spectrometer using the ED-XRF method, which could be performed without significant damage to these historical pieces. In addition, other methods were used for two samples of door handles, namely the glow discharge optical emission spectrometry (GDOES) and metallographic analysis, which were, however, associated with destructive preparation of samples. It was found that four of the door handles samples used for the same type of car had different finishes. Although more modern chrome plating has been used in the Tatra since the early 1930, surprisingly, nickel was used for surface treatment here. There could have been more reasons why this was the case. Most likely, the shutdown of a part of the operation, or the lack of supply in the time of The Second World War, could have caused this phenomenon. The results of the measurements will be used in the production of accurate copies of outer door handles, which are no longer available in the vintage cars market today.
\end{abstract}

Keywords: Door handles, composition, historic vehicle, surface finish

\section{INTRODUCTION}

At present, collecting and care of technical cultural heritage are very popular and thus there is a greater demand for spare parts and production associated with them. This is a complex issue that includes knowledge of material engineering, methods of reverse engineering [1,2] and, last but not least, of production technology.

Electrolytic nickel galvanization is one of the oldest techniques used, for electrolytic excretion procedures in metals. Nickel (Ni) is mainly used for decorative purposes on technical products made of copper, copper alloys (brass, bronze) and iron. Nickel is applied to a layer of copper $(\mathrm{Cu})$. Nickel is characterized by very good corrosion resistance, especially in atmospheric conditions [3,4]. A large part of the parts in cars and motorcycles was nickel-plated until 1930 [4]. 
Chrome plating is a galvanic (electro-chemical) application of several layers of metals to the prepared base. The layers are applied in order of copper $(\mathrm{Cu})$, nickel $(\mathrm{Ni})$ and chrome $(\mathrm{Cr})$. This finish is mainly used for its characteristic gloss, but the treated surfaces also show very good mechanical resistance [4].

Modern decorative solutions for nickel plating contain organic additives and ensure that mirrored shiny, highplanar nickel coatings are released directly from the solution. Prior to the introduction of these organic admixture baths, decorative nickel coatings were produced by mechanical polishing of nickel-plated components, which was practiced between 1870 and approximately 1945. In 1927, for the first time, thin layers of chromium were electrolytically applied to polished nickel coatings to prevent yellowing or scratching of nickel coatings. Multi-layer nickel coatings began to be used in the early 1950 s and micro-discontinuous chromium coatings from the mid-1960s to early 2000s. Modern multi-layer nickel coatings in combination with microdiscontinuous chrome can protect and improve the appearance of most metals and alloys, plastics and other materials in the long term [5].

The material analysis consisted of determining the chemical composition of the external doors handles mounted on Tatra 87 cars and of their microstructure. There were four handles about different condition and age that did not come from one car. Individual samples were marked $A$ to $D$. The article also mentions surface finishes, which differed surprisingly for each handle.

\section{ANALYSIS OF SAMPLES A, B}

At first glance, the door handles $A$ and $B$ differed in appearance. The handle $A$ had a matte, rough surface (Figure 1). The $B$ handle showed that the surface was coated with a metallic glossy layer but damaged by uneven corrosion (Figure 1). For handles A and B (Figure 1), only the chemical composition using an X-ray spectrometer has been evaluated, using Delta Professional by ED-XRF method due to cause the least damage to historical handles. The disadvantage of this method is that it does not allow for steels to reliably determine the carbon content and therefore the given quality of the steel. First, measurements were made on the degreased surface, than the handles have been ground at the point of attachment to the bodywork to remove the surface layer and provide a place to measure the chemical composition of the base material (Figure 2). It was found that the handle $A$ did not contain a surface layer and was made of non-alloy, carbon steel (Table 1). A high nickel and copper content were detected on the surface of handle B implying that this one was surface-treated using nickel, with copper being used as the underlying layer (Table 1). After the surface was ground, in the analysis of the chemical composition of the base material, there is an increased percentage of $\mathrm{Ni}$ and $\mathrm{Cu}$, but this analysis is affected by the surrounding surface, which has not been ground (Table 2). The base material is expected to be carbon steel again.

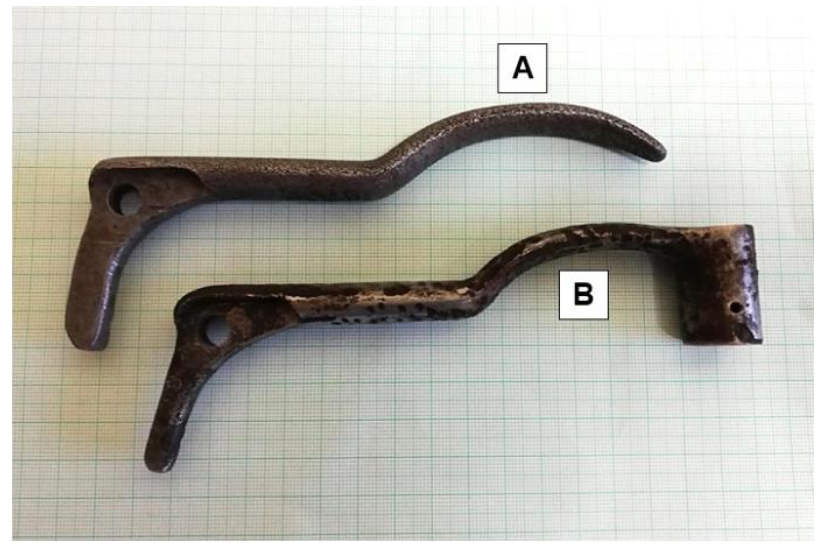

Figure 1 Door handles A and B

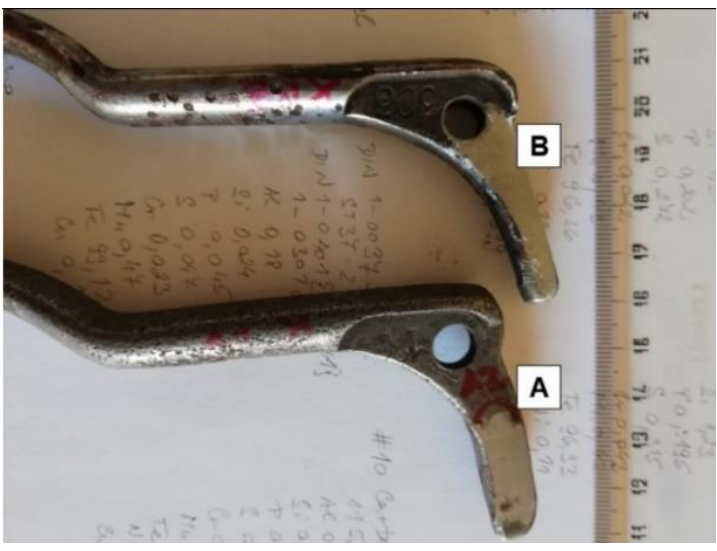

Figure 2 Detail of the surface and place of measurement of chemical composition using the ED-XRF method 
Table 1 The chemical composition of handle A and B determined by the ED-XRF method in wt\% (note.: affected by oxidation, does not include oxygen and carbon)

\begin{tabular}{|c|c|c|c|c|c|}
\hline \multicolumn{3}{|c|}{ Handle A } & \multicolumn{3}{c|}{ Handle B } \\
\hline Element & $\begin{array}{c}\text { No surface } \\
\text { grinding }\end{array}$ & $\begin{array}{c}\text { After grinding } \\
\text { the surface }\end{array}$ & Element & $\begin{array}{c}\text { No surface } \\
\text { grinding }\end{array}$ & $\begin{array}{c}\text { After grinding } \\
\text { the surface }\end{array}$ \\
\hline $\mathrm{Si}$ & 1.75 & 0.05 & $\mathrm{Si}$ & 0.70 & 0.76 \\
\hline $\mathrm{Mn}$ & 0.43 & 0.47 & $\mathrm{Mn}$ & 0.10 & 0.46 \\
\hline $\mathrm{Al}$ & 0.93 & 0.19 & $\mathrm{Al}$ & 0.50 & 0.38 \\
\hline $\mathrm{Cr}$ & 0.03 & 0.02 & $\mathrm{Cr}$ & 0.51 & 0.03 \\
\hline $\mathrm{P}$ & 0.18 & 0.04 & $\mathrm{P}$ & - & 0.03 \\
\hline $\mathrm{S}$ & 0.34 & 0.04 & $\mathrm{~S}$ & 0.46 & 0.07 \\
\hline $\mathrm{Ni}$ & 0.17 & 0.04 & $\mathrm{Ni}$ & $\mathbf{3 4 . 2 2}$ & 6.84 \\
\hline $\mathrm{Cu}$ & 0.61 & 0.12 & $\mathrm{Cu}$ & 47.17 & 5.28 \\
\hline $\mathrm{Fe}$ & rest & rest & $\mathrm{Fe}$ & rest & rest \\
\hline
\end{tabular}

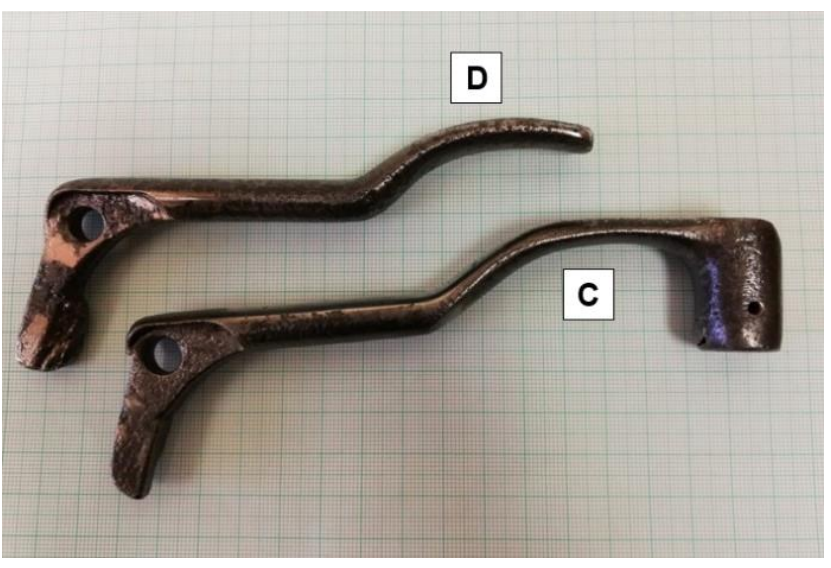

Figure 3 Door handles $C$ and $D$

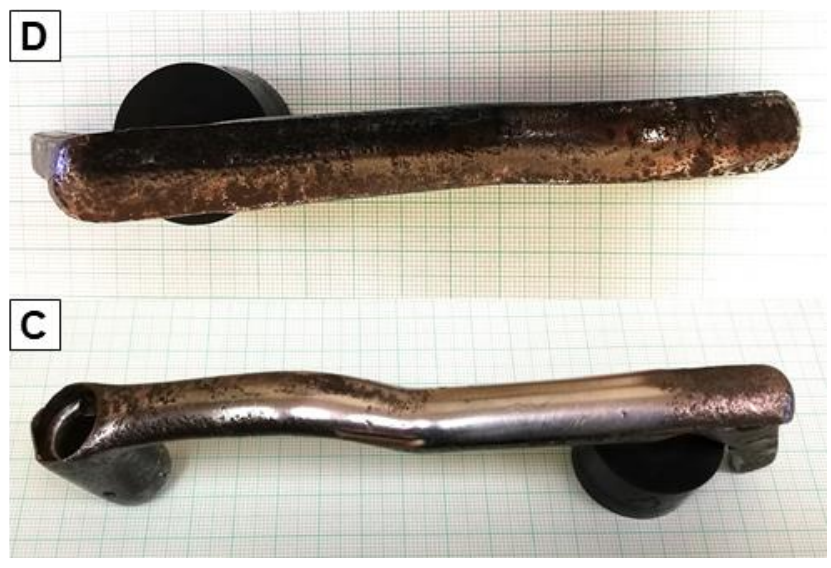

Figure 4 Handles $C$ and D surfaces

It was possible to cut the $C$ and $D$ handles (Figures 3 and 4 ) and perform a metallographic analysis on them and measurement of chemical composition using a more precise method of optical emission spectrometry with smouldering discharge (GDOES) on GDA 750 produced by Spektruma company, which also allows the carbon content to be measured [6,7]. For comparison with previous handles, a chemical composition measurement was also made using the Delta Professional X-ray spectrometer using the ED-XRF method. Both C and D handles were coated (Figures 3 and 4), which shows the presence of a glossy surface. For handle D, a layer of copper was visible under a glossy surface layer. Both handles were attacked by uneven corrosion, although more pronounced corrosion was observed with handle D (Figure 3). The handle $C$ was coated with chrome layer as opposed to the handle $D$, coated with a nickel layer beneath which was a layer of copper (Table 2). The basic material consisted of non-alloy, carbon steel (Table 2 and Table 3). GDOES analysis found that the handle $\mathrm{C}$ was made of carbon-containing steel $0.30 \mathrm{wt} \%$ and the $\mathrm{D}$ handle of carbon-containing steel of 0.17 wt\% (Table 3).

The microstructure of the handles was analyzed on x-section metallographic cut-outs using the Olympus GX51 light microscope (abbreviated LM) in a polished and etched state in $4 \% \mathrm{HNO}_{3}$ solution in alcohol (Nital). On the lower and lateral parts of the handles, you can see uneven corrosion on the surface, reaching a depth of 50-100 $\mu \mathrm{m}$ (Figure 5), in an etched state it is a very thin (units of micrometres) surface layer (Figure 6). In the 
microstructure in the polished state, non-metallic inclusions based on MnS are visible (Figure 7 and Figure 9), to a greater extent for handle C (Figure 7), corresponding to the increased sulphur content (Table 3). Also, some coarser inclusions of the alumina type were found. After etching in the Nital solution, the ferritic-perlitic microstructure occurred (Figures 8 and 10). For the top surface of handle $C$, the microstructure contains slightly coarser grains of pearlite than there is on the side and bottom. The pearlite proportion was lower for handle D, corresponding to the lower carbon content of the matrix (Figures 8 and 10).

Table 2 Chemical composition of handles $\mathrm{C}$ and $\mathrm{D}$ determined by ED-XRF method in wt\% (note: affected by oxidation, does not include oxygen and carbon)

\begin{tabular}{|c|c|c|c|c|c|}
\hline \multicolumn{3}{|c|}{ Handle C } & \multicolumn{3}{c|}{ Handle D } \\
\hline Element & $\begin{array}{c}\text { No surface } \\
\text { grinding }\end{array}$ & $\begin{array}{c}\text { After grinding } \\
\text { the surface }\end{array}$ & Element & $\begin{array}{c}\text { No surface } \\
\text { grinding }\end{array}$ & $\begin{array}{c}\text { After grinding } \\
\text { the surface }\end{array}$ \\
\hline $\mathrm{Si}$ & 0.24 & 0.15 & $\mathrm{Si}$ & 0.31 & 0.21 \\
\hline $\mathrm{Mn}$ & - & 0.45 & $\mathrm{Mn}$ & 0.34 & 0.53 \\
\hline $\mathrm{Al}$ & - & 0.20 & $\mathrm{Al}$ & - & 0.15 \\
\hline $\mathrm{P}$ & - & 0.03 & $\mathrm{P}$ & 0.03 & 0.04 \\
\hline $\mathrm{S}$ & 0.05 & 0.13 & $\mathrm{~S}$ & 0.24 & 0.09 \\
\hline $\mathrm{Cr}$ & 20.82 & 0.03 & $\mathrm{Cr}$ & 0.74 & 0.03 \\
\hline $\mathrm{Ni}$ & - & 0.04 & $\mathrm{Ni}$ & $\mathbf{1 6 . 5 9}$ & 0.07 \\
\hline $\mathrm{Cu}$ & 0.13 & 0.20 & $\mathrm{Cu}$ & $\mathbf{1 4 . 0 9}$ & 0.32 \\
\hline $\mathrm{Fe}$ & rest & rest & $\mathrm{Fe}$ & rest & rest \\
\hline
\end{tabular}

Table 3 Chemical composition of the base material in handles $C$ and D determined by the GDOES method in wt\%

\begin{tabular}{|c|c|c|c|c|c|c|c|c|c|}
\hline Handle & $\mathbf{C}$ & $\mathbf{M n}$ & $\mathbf{S i}$ & $\mathbf{P}$ & $\mathbf{S}$ & $\mathbf{C r}$ & $\mathbf{N i}$ & $\mathbf{C u}$ & $\mathbf{F e}$ \\
\hline C & 0.30 & 0.50 & 0.01 & 0.043 & 0.063 & 0.03 & 0.05 & 0.19 & rest \\
\hline $\mathbf{D}$ & 0.17 & 0.56 & $<0.001$ & 0.033 & 0.033 & 0.04 & 0.08 & 0.26 & rest \\
\hline
\end{tabular}

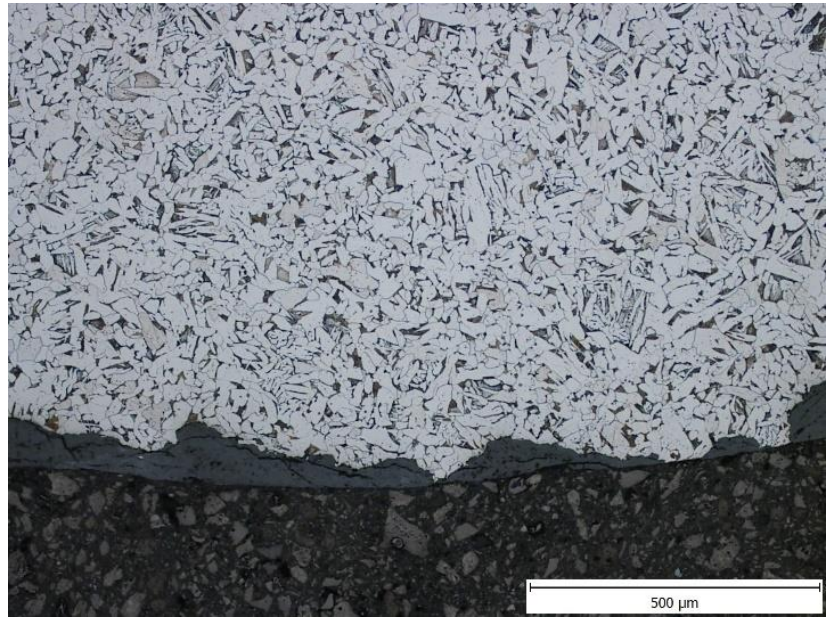

Figure 5 Microstructure of door handle D, surface with corrosion, etched in Nital (LM)

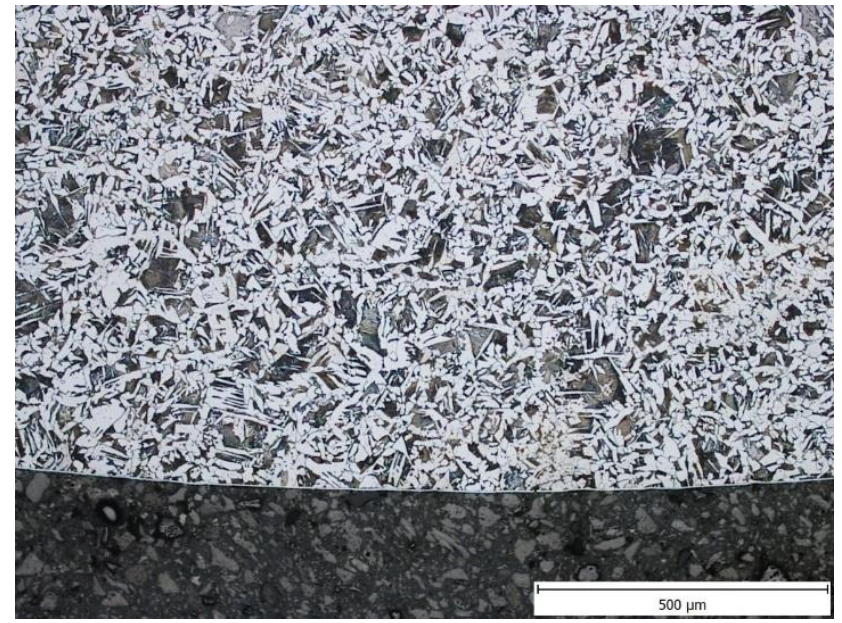

Figure 6 Microstructure of door handle C, surface with a thin layer, etched in Nital (LM) 


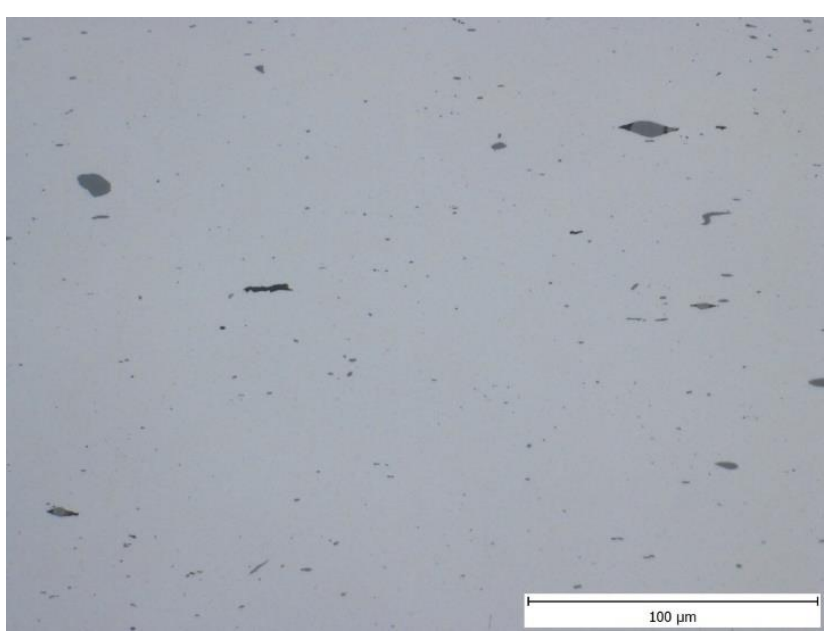

Figure 7 Door handle C, polished state, inclusions

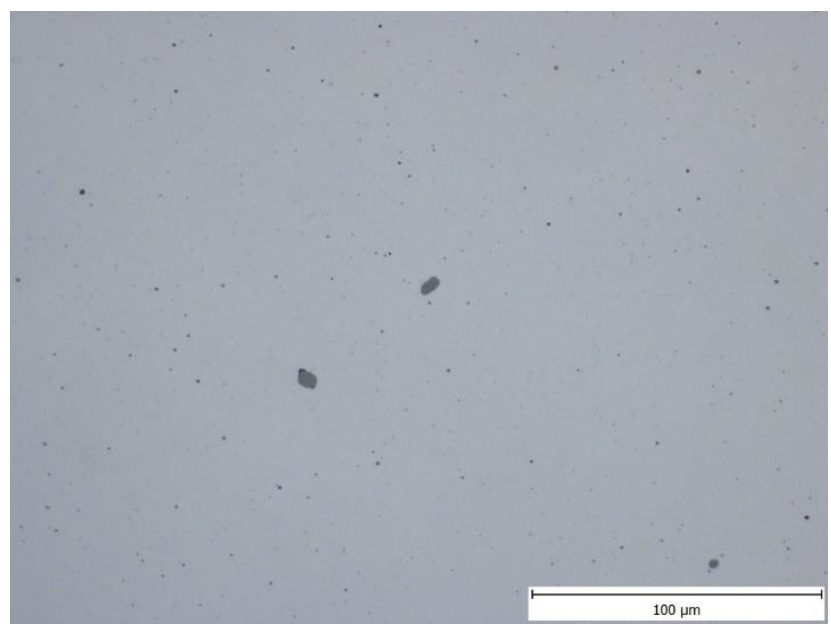

Figure 9 Door handles D, polished state, inclusions

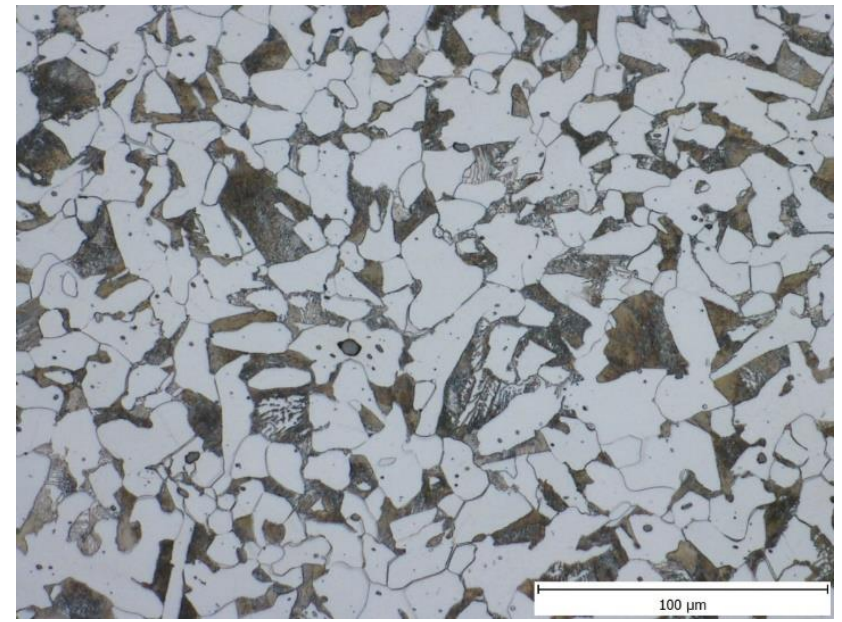

Figure 8 Microstructure of door handle $\mathrm{C}$, etched in Nital (LM)

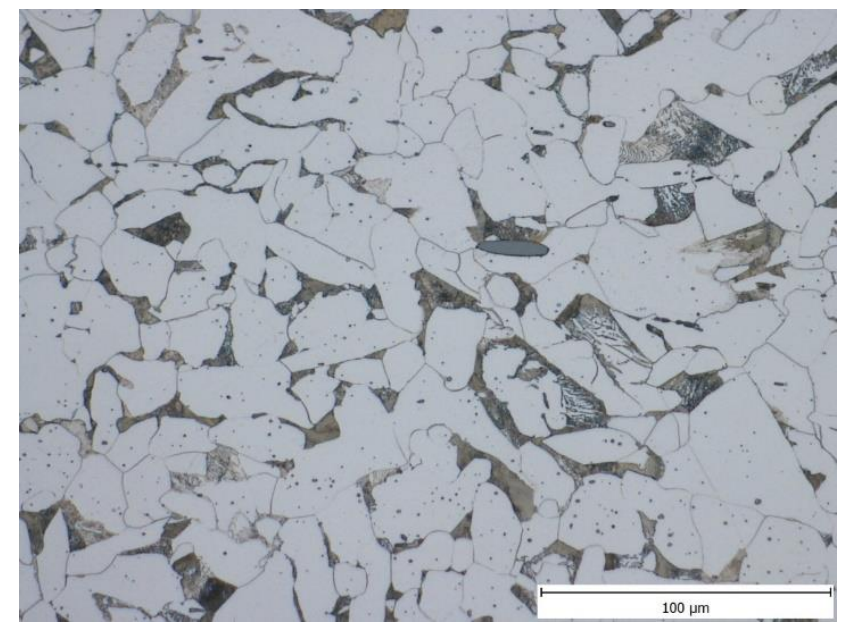

Figure 10 Microstructure of door handles D, etched in Nital (LM)

On $C$ and $D$ handles hardness measurement scan according to Vickers HV 30 in compliance with the ČSN EN ISO 6507-1 was done. The $C$ handle had the hardness of $144 \pm 3$ HV30. The D handle had a lower hardness, i.e. $124 \pm 1 \mathrm{HV} 30$, corresponding to a smaller amount of carbon in the matrix.

\section{CONCLUSION}

Analysis of the chemical composition of the external handles from the Tatra 87 car was carried out to obtain information on the material that was used to produce the part for this vintage car. The result from the measurement can be used for the production of a new part, which can replace either the missing part or the part in an already unrecoverable state. The issue connected with the production of parts for vintage means of transport or technical monuments is generally very extensive. It is important to maintain the production processes and materials. For this reason, material analysis is of great importance and in the future, we will not be allowed to avoid it in the restoration of cultural technical monuments. The information found may assist restorers in the manufacture or repair of damaged parts. The results obtained can be used on the Tatra 97, which used the same outer handles as the larger car Tatra 87. 


\section{ACKNOWLEDGEMENTS}

Innovation of Modern Technologies in Manufacturing Practice, reg. no. SP2020/1 supported by Specific Research program financed by the Ministry of Education, Youth and Sports.

\section{REFERENCES}

[1] DURNA, A., FRIES, J. Universal Machine for Prototype Production. MM Science Journal. 2020, no. 3, pp. 37693773.

[2] DURNA, A., FRIES, J., HRABOVSKÝ, L., SLÍVA, A., ŽARNOVSKÝ, J. Research and Development of Laser Engraving and Material Cutting Machine from 3D Printer. Management Systems in Production Engineering, 2020, vol. 28 , no. 1 , pp. 47-52.

[3] http://galvanika.cz/niklovani.html

[4] http://www.superchrom.cz/niklovani-super-chrom-cz/

[5] LAMPMAN, S., Tina, M., LUCARELLI, K.F., Nikki, D.W., WOODS,M.S. ASM Handbook. Volume 5, Surface Engineering. Materials Park: ASM International, 1994.

[6] VONTOROVÁ, J., MOHYLA, P. Use of GDOES method for evaluation of the quality and thickness of hot dip galvanised coating. Transactions of the Institute of Metal Finishing. 2018, vol. 96, no. 6, pp. 313-318.

[7] VONTOROVÁ, J., DOBIÁŠ, V., MOHYLA, P. Utilization of GDOES for the study of friction layers formed on the surface of brake discs during the friction process. Chemical Papers. 2017, vol. 71, no. 8, pp. 1507-1514. 